\title{
Elevated levels of soluble E-selectin in patients with IDDM and NIDDM: relation to metabolic control
}

\author{
L.Cominacini ${ }^{1}$, A. Fratta Pasini ${ }^{1}$, U. Garbin ${ }^{1}$, A.Davoli ${ }^{1}$, A.De Santis ${ }^{1}$, M. Campagnola ${ }^{1}$, A. Rigoni ${ }^{1}$, M. G.Zenti ${ }^{2}$, \\ P. Moghetti ${ }^{2}$, V. Lo Cascio ${ }^{1}$ \\ ${ }^{1}$ Istituto di Semeiotica e Nefrologia Medica, Università di Verona, Verona, Italy \\ ${ }^{2}$ Cattedra di Malattie del Metabolismo, Università di Verona, Verona, Italy
}

\begin{abstract}
Summary The adhesion of leucocytes to the endothelium, an early step in atherogenesis, is mediated by cell adhesion molecules. In this study we evaluated the concentration of soluble adhesion molecules in patients with insulin-dependent (IDDM) and non-insulin-dependent diabetes mellitus (NIDDM) and studied its relation to glycaemic control. Soluble adhesion molecules E-selectin, intercellular adhesion molecule-1 (ICAM-1) and vascular adhesion molecule-1 (VCAM-1) were measured in 31 diabetic patients (18 with IDDM and 13 with NIDDM), 20 hyperlipoproteinaemic patients (10 with type II a and 10 with type $\mathrm{II}$ ) and 20 healthy subjects. Increased Eselectin concentrations were found in the patients with IDDM and NIDDM and in the hyperlipoproteinaemic patients when compared to the control subjects $(p<0.01$ for all the groups). ICAM-1 was found to be elevated only in the patients with
\end{abstract}

NIDDM $(p<0.01)$. No significant differences in VCAM-1 concentration were found in the different groups of subjects. The concentration of plasma E-selectin was positively correlated with the glycated haemoglobin $(r=0.54, p<0.01)$ in patients with IDDM and NIDDM. In the same patients E-selectin was not related to the concentrations of plasma lipids in spite of the fact that it was found to be elevated in hyperlipoproteinaemic subjects. The results though preliminary suggest that in diabetic patients the concentration of soluble adhesion molecules and especially of E-selectin may be related to metabolic control. [Diabetologia (1995) 38: 1122-1124]

Key words Diabetes mellitus, insulin-dependent diabetes mellitus, non-insulin-dependent diabetes mellitus, adhesion molecules, E-selectin, ICAM-1, VCAM-1.
A large body of evidence shows that leucocytes are involved in the pathogenesis of atherosclerosis [1]. The earliest morphological evidence of the disease is the attachment of monocytes to the intact endothelium, that is followed by subendothelial accumulation of macrophages, which become lipid-laden foam cells [2]. This enhanced recruitment of monocytes to endothelium is likely to be due to the appearance at the cell

Received: 14March 1995 and in revised form: 5June 1995

Corresponding author: L. Cominacini, M. D., Istituto di Semeiotica e Nefrologia Medica, Università di Verona Ospedale Policlinico, I-37134 Verona, Italy

Abbreviations: IDDM, insulin-dependent diabetes mellitus; NIDDM, non-insulin-dependent diabetes mellitus; ICAM-1, intercellular adhesion molecule-1; VCAM-1, vascular adhesion molecule-1; AGE, advanced glycation end products. surface of adhesion molecules, which include E-selectin (a specific product of endothelial cells), intercellular adhesion molecule-1 (ICAM-1) and vascular cell adhesion molecule-1 (VCAM-1) (both the product of endothelial cells and other cells). E-selectin is of particular interest because, in contrast to other adhesion molecules, it is expressed only on activated endothelium [3]. The demonstration of soluble E-selectin in the blood would therefore be taken as evidence of endothelial activation. Recent studies have reported increased levels of E-selectin in patients with hypertension [4] and diabetes mellitus [5]. In the latter paper, however, the type of diabetes and the possible relation to glycaemic control were not mentioned.

In this study we evaluated the concentrations of the soluble adhesion molecules and particularly of E-selectin in patients with insulin-dependent (IDDM) 
Table 1. Anthropometric characteristics and serum concentrations of adhesion molecules in the subjects studied

\begin{tabular}{|c|c|c|c|c|c|}
\hline $\begin{array}{l}\text { Subjects } \\
n\end{array}$ & $\begin{array}{l}\text { IDDM } \\
18\end{array}$ & $\begin{array}{l}\text { NIDDM } \\
13\end{array}$ & $\begin{array}{l}\text { Type II a } \\
10\end{array}$ & $\begin{array}{l}\text { Type IIb } \\
10\end{array}$ & $\begin{array}{l}\text { Control subjects } \\
20\end{array}$ \\
\hline Age (years) & $36 \pm 12$ & $46 \pm 8$ & $57 \pm 12$ & $59 \pm 9$ & $42 \pm 11$ \\
\hline Sex (male/female) & $9 / 9$ & $9 / 4$ & $5 / 5$ & $5 / 5$ & $10 / 10$ \\
\hline $\mathrm{Ch}(\mathrm{mmol} / \mathrm{l})$ & $4.91 \pm 0.46$ & $5.01 \pm 0.98$ & $7.88 \pm 1.94^{\mathrm{a}}$ & $7.34 \pm 0.62^{\mathrm{a}}$ & $4.57 \pm 0.83$ \\
\hline $\mathrm{Tg}(\mathrm{mmol} / \mathrm{l})$ & $0.91 \pm 0.38$ & $1.40 \pm 0.39$ & $0.90 \pm 0.36$ & $2.82 \pm 0.82^{\mathrm{a}}$ & $0.89 \pm 0.37$ \\
\hline $\mathrm{LDL}$ Ch $(\mathrm{mmol} / \mathrm{l})$ & $3.18 \pm 0.49$ & $3.44 \pm 0.81$ & $5.79 \pm 2.04^{\mathrm{a}}$ & $4.78 \pm 0.52^{\mathrm{a}}$ & $2.74 \pm 0.62$ \\
\hline E-selectin $(\mu \mathrm{g} / \mathrm{l})$ & $44.4 \pm 15.4^{\circ}$ & $50.4 \pm 27.1^{\mathrm{c}}$ & $41.1 \pm 10.9^{c}$ & $40.2 \pm 10.1^{c}$ & $33.1 \pm 7.8$ \\
\hline ICAM-1 $(\mu \mathrm{g} / 1)$ & $280.5 \pm 125.7$ & $302.3 \pm 99.9^{c}$ & $225.4 \pm 66.2$ & $197.1 \pm 61.4$ & $229.4 \pm 51.5$ \\
\hline VCAM-1 ( $\mu \mathrm{g} / \mathrm{l})$ & $542.6 \pm 158.2$ & $551.4 \pm 203.4$ & $411.7 \pm 113.5$ & $436.9 \pm 85.9$ & $501.8 \pm 98.5$ \\
\hline
\end{tabular}

Data are mean $\pm \mathrm{SD}$

a Significantly different from control subjects, IDDM and NIDDM patients $p<0.01 ;{ }^{b}$ significantly different from control subjects and IDDM patients $p<0.01 ;^{\mathrm{c}}$ significantly higher than control subjects $p<0.01$

and non-insulin-dependent diabetes (NIDDM) and studied its relation to glycaemic control.

\section{Subjects and methods}

We studied 31 diabetic patients, 20 patients with familial hyperlipoproteinaemia and 20 control subjects. The diabetic patient group comprised 18 IDDM patients ( 9 men and 9 women) aged (mean \pm SD) $36 \pm 12$ years, with a body mass index (BMI) of $23 \pm 2 \mathrm{~kg} / \mathrm{m}^{2}$, and 13 NIDDM patients $(9$ men and 4 women) aged $46 \pm 8$ years, with a BMI of $27 \pm 4 \mathrm{~kg} / \mathrm{m}^{2}$. All these subjects had plasma cholesterol less than $6.20 \mathrm{mmol} / 1$ and triglycerides less than $2.26 \mathrm{mmol} / 1$ and were in poor glycaemic control (glycated haemoglobin $7.3 \pm 1.1$ and $7.0 \pm 1.2 \%$, respectively for IDDM and NIDDM patients).

To evaluate the possible effects of plasma lipids on the soluble adhesion molecules, 10 type $\Pi$ a ( 5 men and 5 women) aged $57 \pm 12$ years with a BMI of $24 \pm 3 \mathrm{~kg} / \mathrm{m}^{2}$ and 10 type II b dyslipidaemic patients ( 5 men and 5 women), aged $59 \pm 9$ years with a BMI of $29 \pm 5 \mathrm{~kg} / \mathrm{m}^{2}$ were studied. Mean total cholesterol was $7.88 \pm 1.94 \mathrm{mmol} / \mathrm{l}$ for type II a and $7.34 \pm 0.62 \mathrm{mmol} / \mathrm{l}$ for type IIb dyslipidaemic patients. The control subjects (10 men and 10 women), aged $42 \pm 11$ years with a BMI of $23 \pm 4 \mathrm{~kg} / \mathrm{m}^{2}$ were members of the hospital staff.

All the patients with IDDM and 1 with NIDDM were treated by insulin; the remaining 12 patients with NIDDM were treated with oral hypoglycaemic agents. All the hyperlipoproteinaemic subjects were consuming a lipid-lowering diet and 4 of these were submitted to a hypolipidaemic treatment. Three patients with IDDM, two with hyperlipoproteinaemia and four control subjects were habitual smokers. In all the subjects renal impairment, liver diseases, malignancies and pathological processes known to increase adhesion molecules were excluded. Venous blood was collected at 08.00 hours, after $12 \mathrm{~h}$ of fasting, using vacutainer tubes and maintained at room temperature for a minimum of $1 \mathrm{~h}$. Serum was extracted following 10 -min centrifugation in a bench centrifuge at $2500 \mathrm{rev} / \mathrm{min}$ and was stored at $-20^{\circ} \mathrm{C}$ until assayed. Levels of soluble E-selectin, ICAM-1 and VCAM-1 were estimated using the soluble E-selectin, ICAM-1, VCAM-1 ELISA KITS (British Bio-technology Products Ltd, AbingdonOxon, UK). Plasma glucose was measured by the glucose oxidase method on a Beckman glucose analyzer (Beckman, Instruments Inc., Palo Alto, CA, USA). Glycated haemoglobin in plasma was measured by using a minicolumn chromato- graphic procedure [6]. Cholesterol and triglycerides in plasma and lipoprotein fractions were determined by Technicon autoanalyzer II (Technicon, Instruments Corp., Tarrytown, NY, USA) methodology. Lipoprotein fractions were isolated by sequential ultracentrifugation in $\mathrm{NaBr}$ solutions.

\section{Statistical analysis}

Values are expressed as mean \pm SD. Statistical differences between groups were tested using the Mann-Whitney U-test, after the Kruskal-Wailis test had been applied (Statview 512 on an Apple Macintosh).

\section{Results and discussion}

Table 1 shows the mean values of the anthropometric characteristics, total cholesterol, triglycerides, lipoprotein lipids in the IDDM, NIDDM, dyslipidaemic (type II a and IIb) patients and in the control subjects. Table 1 also shows the values of glycated haemoglobin in the IDDM and NIDDM patients. Total cholesterol and LDL cholesterol was significantly higher in the type II a and II b dyslipidaemic patients than in the control subjects $(p<0.01)$. Total triglycerides were significantly higher only in the type II b patients $(p<0.01)$. Lipid concentrations in the IDDM and NIDDM patients were similar to those found in the control subjects.

Table 1 also shows the mean values of serum concentrations of E-selectin, ICAM-1 and VCAM-1 in the IDDM, NIDDM, dyslipidaemic patients and in the control subjects. E-selectin concentrations were significantly higher in the diabetic (both IDDM and NIDDM) and hyperlipoproteinaemic patients than in the control subjects $(p<0.01)$. The values of ICAM-1, on the contrary, were significantly higher only in the NIDDM patients when compared to the control subjects $(p<0.01)$. No significant differences in VCAM concentrations were found in the different 


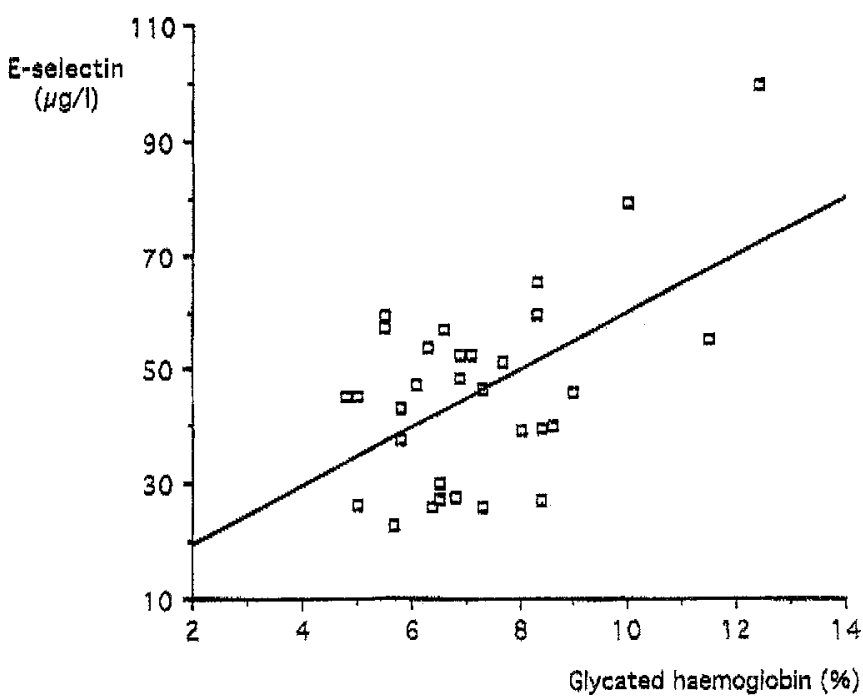

Fig. 1. Relationship between glycated haemoglobin (\%) and concentrations of serum E-selectin $(\mu \mathrm{g} / \mathrm{l})$ in the diabetic patients $(y=9.4543+5.0967 x ; r=0.54, p<0.01)$

groups of subjects. E-selectin concentrations were significantly correlated with glycated haemoglobin in both IDDM and NIDDM patients (respectively, $r=0.51, p<0.01$ and $r=0.59, p<0.01$ ) and in all the diabetic patients $(r=0.54, p<0.01)$ (Fig. 1). E-selectin concentrations, on the contrary, were never correlated with the lipid levels in the two groups or in the whole group of diabetic or dyslipidaemic patients.

On the basis of the present results, assessing the physiological significance, if any, of an increased amount of soluble adhesion molecules in diabetes is difficult. It is worth noting, however, that the expression of E-selectin in endothelial cells is induced at the transcriptional level by interleukin- $1 \beta$ and tumour necrosis factor- $\alpha$ [7]. Although soluble E-selectin is released after being expressed in vitro [8], until now it has not been known whether it is also a marker of cell activation in vivo. Therefore, we can only suggest that the increased levels of E-selectin found in our patients may be the expression of endothelium activation. It must be pointed out, however, that in diabetes the extended interaction of aldoses with proteins can lead (after a slow, complex series of chemical rearrangements) to the formation of irreversible advanced glycosylation end products (AGEs) of proteins [9] and the rate of this accumulation is proportional to the time-integrated blood glucose level over long periods of time [9]. AGEs have recently been demonstrated to induce, in a distinct time course, the expression of different adhesion molecules, especially of E-selectin, on the endothelial cells [9]. Since it has been proposed that the AGE accumulation might be prevented if the reactive intermediates of early glycosylation products are blocked [9], it is likely that the amount of early glycosylation products, for example glycated haemoglobin, may be, at least in part, related to the AGE formation and consequently to endothelial cell activation. In this study glycated haemoglobin was positively correlated with the serum E-selectin concentration, suggesting that the metabolic control of the diabetic patients may somehow affect the endothelial cell activity. Further prospective studies in larger groups of patients are needed to support this hypothesis.

In this study E-selectin concentration was not related to plasma lipids in IDDM and NIDDM patients in spite of the fact that E-selectin was found to be elevated in hyperlipoproteinaemic patients. It should be noted, however, that the plasma lipid concentration found in our diabetic patients was similar to that found in the control subjects. In agreement with the demonstration of an enhanced adhesion of monocytes in animals with high cholesterol levels [10], this suggests that only a consistent increase in plasma lipids and in cholesterol in particular may represent a stimulus for endothelial cells. The lack of correlation between E-selectin concentrations and plasma cholesterol even in dyslipidaemic patients, however, does not help to explain this connection.

\section{References}

1. Ross R (1986) The pathogenesis of atherosclerosis - an update. N Engl J Med 314: 488-500

2. Faggiotto A, Ross R, Harker L (1984) Studies of hypercholesterolemia in the nonhuman primate. Arteriosclerosis 4: 323-340

3. Gearing AJH, Newman W (1993) Circulating adhesion molecules in disease. Immunol Today 14: 506-512

4. Blann AD, Tse W, Maxwell SJR, Waite MA (1994) Increased levels of the soluble adhesion molecule E-selectin in essential hypertension. J Hypertension 12: 925-928

5. Gearing AJH, Hemingway I, Pigott R, Hughes J, Rees AJ, Cashman SJ (1992) Soluble forms of vascular adhesion molecules, E-Selectin, ICAM-1 and VCAM-1: pathological significance. Annals NY Acad Sci 667: 324-331

6. Jaynes PK, Willis MC, Chou PP (1985) Evaluation of a mini-column chromatographic procedure for the measurement of haemoglobin $\mathrm{A}_{1 \mathrm{c}^{*}}$. Clin Biochem 18: 32-36

7. Whelan J, Ghersa P, van Huijssduijnen RH et al. (1991) An NF-kB-like factor is essential but not sufficient for cytokine induction of endothelial leukocyte adhesion molecule 1 (ELAM-1) gene transcription. Nucleic Acid Res 19: 26452653

8. Pigott R, Dillon LP, Hemingway I, Gearing AJH (1992) Soluble forms of E-selectin, ICAM-1 and VCAM-1 are present in the supernatants of cytokine activated cultured endothelial cells. Biochem Biophys Res Commun 187: 584-589

9. Brownlee M, Cerami A, Vlassara H (1988) Advanced glycosylation end products in tissue and the biochemical basis of diabetic complications. N Engl J Med 318: 1315-1321.

10. Joris I, Zand T, Nunnari JJ, Krolikowsky FJ, Majno G (1983) Studies on the pathogenesis of atherosclerosis I. Adhesion and migration of mononuclear cells in the aorta of hypercholesterolemic rats. Am J Path 113: 341-358 